\title{
Circulating Tumor Cells for Predicting the Prognostic of Patients with Hepatocellular Carcinoma: A Meta Analysis
}

\author{
Jun-Li Fan ${ }^{\mathrm{a}}$ Yi-Fei Yang ${ }^{\mathrm{b}}$ Chun-Hui Yuan ${ }^{\mathrm{a}}$ Hao Chen ${ }^{\mathrm{a}}$ Fu-Bing Wang ${ }^{\mathrm{a}}$
}

aDepartment of Laboratory Medicine, Zhongnan Hospital of Wuhan University, Wuhan, ${ }^{b}$ Department of Immunology, College of Medicine, Wuhan University, Wuhan, P.R. China

\section{Key Words}

Hepatocellular carcinoma (HCC) • Circulating tumor cells (CTC) • Prognosis • Clinicopathologic parameter

\begin{abstract}
Background/Aims: The prognostic value of circulating tumor cells (CTC) detected in hepatocellular carcinoma (HCC) patients is currently under debate. We conducted a metaanalysis of available studies to assess its prognostic value for patients diagnosed with HCC. Methods: Medline, Ovid Database, Embase, The Science Citation Index, and Cochrane library, search was conducted on all studies reporting the outcomes of interest. The studies were set up according to the inclusion/exclusion criteria. Using a random-effects model, meta-analysis was performed using hazard ratio (HR), risk ratio (RR) and their $95 \%$ confidence intervals $(95 \%$ CIs) as effect measures. Heterogeneity of the studies was tested for each pooled analysis. Subgroup and sensitivity analyses were also performed. Results: twenty-three published studies that matched the selection criteria were included in this meta-analysis. CTC positivity was significantly associated with Relapse free survival (RFS) (HR 3.03, 95\% CI: [1.89-4.86]; $p<0.00001$ ) and Overall survival (OS) (HR 2.45, 95\% CI: $[1.73-3.48] ; p<0.00001)$. CTC positivity were also significantly associated with TNM Stage (RR 1.30, 95\% CI: [1.02-1.65]; $p=0.03$ ), Tumor size (RR 1.36, 95\% CI: [1.09-1.69]; $p=0.006)$, Vascular invasion (RR 1.99, 95\% CI: [1.432.77]; $p<0.0001$ ), Portal vein tumor thrombus (RR 1.73, 95\% CI: [1.42-2.11]; $p=0.0001$ ), Serum alpha-fetoprotein (AFP) level (RR 2.05, 95\% CI: [1.18-3.54]; $p=0.01$ ). Conclusion: CTC positivity indicates poor prognosis in patients with hepatocellular carcinoma, and associated with poor clinicopathologic parameters.
\end{abstract}

\section{Introduction}

As one of the most aggressive cancers, hepatocellular carcinoma (HCC) occupies 85\%-90\% of primary liver cancer and it is responsible for significant morbidity and mortality in cirrhosis [1-3]. One-year survival of patients who show progress over the terminal stage is less than $10 \%$

Fu-Bing Wang, MD, PhD

KARGER 125
Department of Laboratory Medicine, Zhongnan Hospital of Wuhan University, No 169 Donghu Road, Wuchang District, Wuhan 430071, (P.R. China)

Tel. +86-27-67813517, Fax +86-27-67813128, E-Mail wfb20042002@sina.com 
[4]. Recently, international consensus was established to choose the best therapeutic method adapted for each case and expected to obtain the best prognosis, however, owing to the lack of precise markers of distant metastasis and recurrence, the prognosis of HCC patients still failed to get significant improvement. Thus, it is undeniable that early detection of tumors and metastasis is urgently needed in medicine [5].

In the field of tumor biology, different types of circulating cellular element have been identified as tumor markers [6, 7]. Circulating tumor cells (CTC) specifically refer to the tumor cells shed into blood, bone marrow or lymphatic vessels. These cells have strong potential of distant metastasis, circulating through the bloodstream, traveling to different tissues or organs of body [8]. Many attempts have been made to develop improved enrichment and identification systems to detect or enumerate CTC [9-11]. As an interesting source of biological information to evaluate dissemination, drug resistance and treatment effectiveness, CTC have been proposed as a monitoring tool in patients with solid tumors, the presence of CTC can reflect the aggressiveness of solid tumors [12-14].

Numerous studies have investigated the prognostic relevance of CTC positivity with the progression of various tumors and proved that CTC could be used to estimate prognosis and may serve as an early marker to assess antitumor activity of treatment, predict relapse free survival (RFS) or overall survival (OS) [15-18]. Although CTC detection has been applied and well documented in different types of cancer, especially breast cancer $[19,20]$, CTC detection remains in the experimental field and is not routinely performed in follow-up of HCC. Thus, with the aim to gain a better insight into the prognostic value of CTC in patients with HCC, we conducted a combined meta-analysis of 23 available studies [21-43] and to determine whether CTC detection indeed provide a more accurately estimate on prognosis of patients with HCC.

\section{Materials and Methods}

\section{Literature Search}

Medline, Ovid Database, Embase, The Science Citation Index, and Cochrane library were systematically searched without time and region restrictions. The following key search terms were used: "Circulating tumor cells" And "Hepatocellular carcinoma (HCC) "And "prognosis". In order to prevent missing relevant publications, the reference lists of the retrieved studies and reviews were also perused manually to check for potentially relevant studies. Cases of disagreement were resolved by discussing the title and abstract; Fulltext articles ( $n=57$ ) were examined and 34 were excluded following the criteria below, and the remaining 23 available studies [21-43] were applied to determine whether CTC detection indeed provide a more accurately estimate on prognosis of patients with HCC.

\section{Study eligibility criteria}

Studies match all of the following inclusion criteria were considered eligible: (1) all enrolled patients were diagnosed with HCC, (2) the samples used in these studies should be peripheral blood, (3) evaluate association between the specific markers of circulating tumor cells and either relapse-free survival (RFS), overall survival (OS), or clinicopathologic parameter of hepatocellular carcinoma, (4) sufficient data to calculate a hazard ratio (HR) or a risk ratio (RR) with a 95\% confidence interval (95\% CI), (5) exclusion of letters to the editor, reviews, and articles published in non-English language, (6) when studies were based on the same patient population, only the most informative study was included.

\section{Data Extraction and quality assessment}

Three reviewers independently extracted data from eligible studies. The following information was extracted: the first author, the year of publication, population characteristics, detection method, the number of cases CTC positivity, prognostic values (OS and RFS), and the number of different clinical and pathological parameters (TNM stage, Tumor size, Vascular invasion, Portal vein tumor thrombus, Tumor number, Serum AFP level). Any disagreements on data extraction and quality assessment of the included studies were resolved through comprehensive discussion and checked by a fourth investigator.

\section{KARGER}


The quality of the included studies was assessed with the Newcastle-Ottawa Scale (NOS) criteria for cohort and case-control studies [44]. Nine points is the perfect score, including three aspects: the definition and selection of the observation group and the control group of the study, comparable of two groups, exposed factors. More than seven points is high quality [45-47].

\section{Statistical Analysis}

Statistical analysis was performed with Review Manager (RevMan-Version5.3.). To statistically evaluate the prognostic effect of CTC, we extracted Hazard Ratio (HR) and their associated standard errors on relapse free survival (RFS) and/or overall survival (OS) from the included studies. We pooled the extracted HRs with the use of the generic inverse variance method in the Review Manager. If the HR and its $95 \%$ confidence interval $(95 \% \mathrm{CI})$ were not provided directly, we calculated from the available data according to the method reported by Tierney J.F. et al [48]. When analyzed the association between CTCs and other parameters, Relative Risk (RR) was calculated. Heterogeneity between studies was tested with the $\mathrm{Q}$ test and $\mathrm{I}^{2}$ statistic. We evaluated potential publication bias by a funnel plot, which was further examined by the Egger [49] using STATA software (Version 12.0, College Station, TX, USA). And pooled analysis of the diagnostic accuracy of CTC positivity was also calculated by STATA. A sensitivity analysis was conducted to assess the quality and consistency of results using the leave-one-out approach.

\section{Results}

\section{Baseline Study Characteristics}

387 studies were initially identified in the literature search. After screening titles and abstracts, 330 studies were excluded and 57 potential studies were reviewed further. An additional 34 studies were then excluded because they were not met the inclusion criteria. Finally, 23 studies were identified as eligible for inclusion in the meta-analysis (Fig. 1).

The included studies encompassed 1785 hepatocellular carcinoma patients and were conducted in 5 countries (China, Germany, France, Netherlands and Italy), published between 1999 and 2014. All studies analyzing peripheral blood, the number of CTC positive patients was 990 and 795 patients were CTC negative. The baseline characteristics and the quality of the included studies evaluated with the NOS are summarized in Table 1.

Fig. 1. Flowchart of the strategy used for the selection of reports used in our analysis. CTC, circulating tumor cells; HCC, hepatocellular carcinoma.

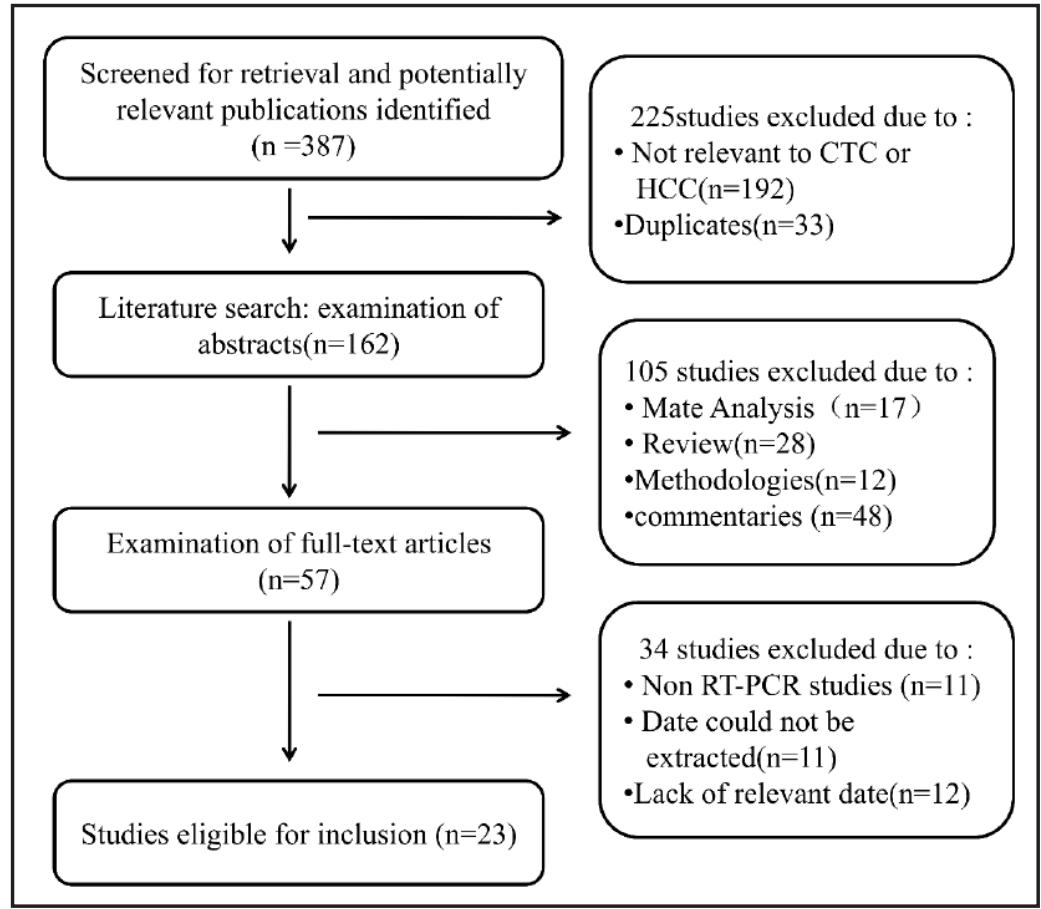


Fan et al.: The Prognostic Value of CTCs in HCC

Table 1. Characteristics of studies included in the meta-analysis. Abbreviations: RT-PCR, reverse transcriptase polymerase chain reaction; NR, not report; ICC, immunocytochemistry; OS, overall survival; RFS, relapse free survival; DFS, disease-free survival; NOS, Newcastle-Ottawa Scale

\begin{tabular}{|c|c|c|c|c|c|c|c|c|}
\hline Reference & Year & $\begin{array}{l}\text { Number of } \\
\text { patients }(\mathrm{M} / \mathrm{F})\end{array}$ & Methods & Positive(\%) & $\begin{array}{l}\text { Tumor } \\
\text { Stage/Grade }\end{array}$ & $\begin{array}{l}\text { Followup } \\
\text { (months) }\end{array}$ & Outcome & NOS \\
\hline Choi,G.h.[21] & 2015 & $63(48 / 15)$ & RT-PCR & $49(77.7 \%)$ & I-IV (Edmondson) & $5-31$ & RFS & 5 \\
\hline Cillo,U.[22] & 2004 & $50(41 / 9)$ & RT-PCR & $20(40 \%)$ & I-IV (TNM) & $1-32$ & RFS/OS & 6 \\
\hline Fan,S,T.[23] & 2011 & $82(67 / 15)$ & CellSearch & $56(68.3 \%)$ & I-IV (TNM) & $1.3-57.1$ & RFS/OS & 5 \\
\hline Jeng, K.S.[24] & 2004 & $81(42 / 39)$ & Other ICC & $19(23.45 \%)$ & I-IV (Edmondson) & $24-60$ & RFS & 6 \\
\hline Rahbari, N.N[25] & 2014 & $63(N R)$ & RT-PCR & $36(57 \%)$ & I-IV (UICC) & $2.9-63.4$ & RFS & 7 \\
\hline Hinz, S.[26] & 2012 & $108(68 / 40)$ & RT-PCR & $42(38.9 \%)$ & I-IV (UICC) & $1-111$ & os & 6 \\
\hline Kong, S.Y.[27] & 2009 & $343(272 / 71)$ & RT-PCR & $204(59.4 \%)$ & I-IV (UICC) & $12-60$ & os & 7 \\
\hline Matsumura,M[28] & 1999 & $88(66 / 22)$ & RT-PCR & $55(63 \%)$ & I-IV (TNM) & $13-46$ & OS & 5 \\
\hline Pilati, P.[29] & 2012 & $50(N R)$ & RT-PCR & $25(50 \%)$ & NR & $4-37$ & os & 6 \\
\hline Kelley,R.K.[30] & 2015 & $20(0 / 20)$ & CellSearch & $8(40 \%)$ & 0-C (BCLC) & $2-25$ & os & 7 \\
\hline Morris,K.L[31] & 2014 & $52(46 / 6)$ & CellSearch & $14(28 \%)$ & II-IV ( TNM ) & 16(Mean) & TTP/OS & 5 \\
\hline $\mathrm{Mu}, \mathrm{H} .[32]$ & 2014 & $62(53 / 9)$ & CellSearch & $30(48.3 \%)$ & I-IV (AJCC) & 24.1-48.5 & OS & 7 \\
\hline Schulze, K.[33] & 2013 & $59(N R)$ & CellSearch & $18(30.5 \%)$ & A-C (BCLC) & $2-36.1$ & OS & 6 \\
\hline Sun, Y.F.[34] & 2013 & $123(115 / 8)$ & CellSearch & $51(41.46 \%)$ & $0-\mathrm{C}(\mathrm{BCLC})$ & $12.3-232$ & TTR & 7 \\
\hline Liu, S.[35] & 2013 & $60(53 / 7)$ & Flow cytometry & $30(50 \%)$ & II-IV (Edmondson) & $3-24$ & DFS/OS & 6 \\
\hline Vona, G.[36] & 2009 & $44(32 / 12)$ & ISET & $23(52.27 \%)$ & NR & $1-40$ & os & 7 \\
\hline Fang, Z.T.[37] & 2014 & $42(9 / 33)$ & CellSearch & $22(52.38 \%)$ & NR & $4-10$ & TTP & 6 \\
\hline $\mathrm{Xu}, \mathrm{W} \cdot[38]$ & 2011 & $85(69 / 16)$ & CellSearch & $69(81 \%)$ & I-IV ( TNM) & NR & NR & 6 \\
\hline Li, Y.M.[39] & 2013 & $60(N R)$ & CellSearch & $46(76.7 \%)$ & I-IV ( TNM ) & NR & NR & 6 \\
\hline Yao,M[40] & 2013 & $123(103 / 20)$ & RT-PCR & $87(70.7 \%)$ & I-IV (TNM) & NR & NR & 6 \\
\hline Li, J.[41] & 2014 & $27(21 / 6)$ & CellSearch & $24(88.9 \%)$ & I-I7 ( TNM) & NR & NR & 7 \\
\hline Mou,D.C[42] & 2001 & $30(21 / 9)$ & RT-PCR & $13(43.3 \%)$ & I-IV (TNM) & $1-33$ & OS & 6 \\
\hline Bahnassy, A.A.[43] & 2014 & $70(67 / 3)$ & Flow cytometry & $39(55.71 \%)$ & I-IV (TNM) & NR & NR & 5 \\
\hline
\end{tabular}

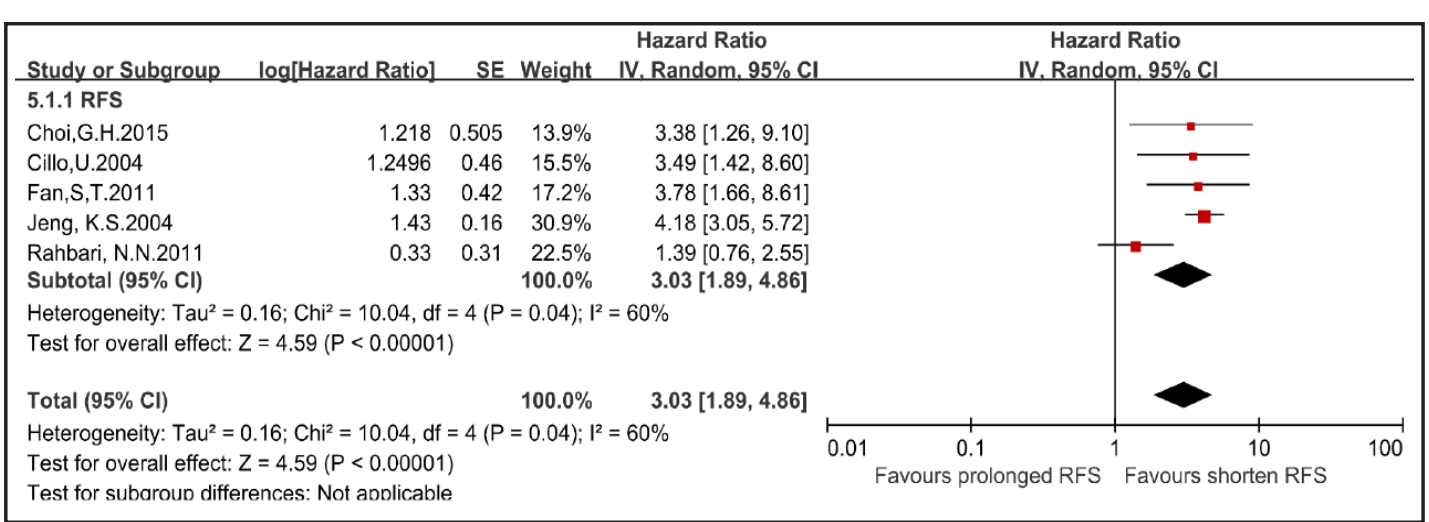

Fig. 2. Summary estimates of hazard ratio (HR) for relapse free survival (RFS) between CTCs-positive and CTCs-negative HCC patients.

\section{Overall analysis of CTC effects on survival of patients with hepatocellular carcinoma}

We extracted Hazard Ratio (HR) and their associated standard errors on relapse free survival (RFS) and/or overall survival (OS) from the included studies, The HR was measured by comparing the CTC positive and CTC negative. HR > 1 implies a poor prognosis in the CTC positive groups. Data on RFS were available in 5 studies [21-25], the pooled analysis showed that the presence of CTC significantly increased the risk of disease recurrence in HCC patients (HR 3.03, 95\% CI: [1.89-4.86]; $p<0.00001$ ) (Fig. 2), as the heterogeneity among studies was moderate $\left(p=0.04, \mathrm{I}^{2}=60 \%\right)$. The HRs for OS were available in 13 studies [21, 24-35]. Pooled analysis showed that CTC positivity was significantly associated with poor OS and increased 


\begin{tabular}{rl|l} 
Cellular Physiology & $\begin{array}{c}\text { Cell Physiol Biochem 2015;37:629-640 } \\
\text { DOI: 10.1159/000430382 }\end{array}$ & $\begin{array}{l}\text { O 2015 S. Karger AG, Basel } \\
\text { www.karger.com/cpb }\end{array}$ \\
and Biochemistry & Published online: September 08, 2015 &
\end{tabular}

Fig. 3. Subgroup analysis by detection method for the difference in OS between CTCs-positive and CTCs-negative HCC patients.

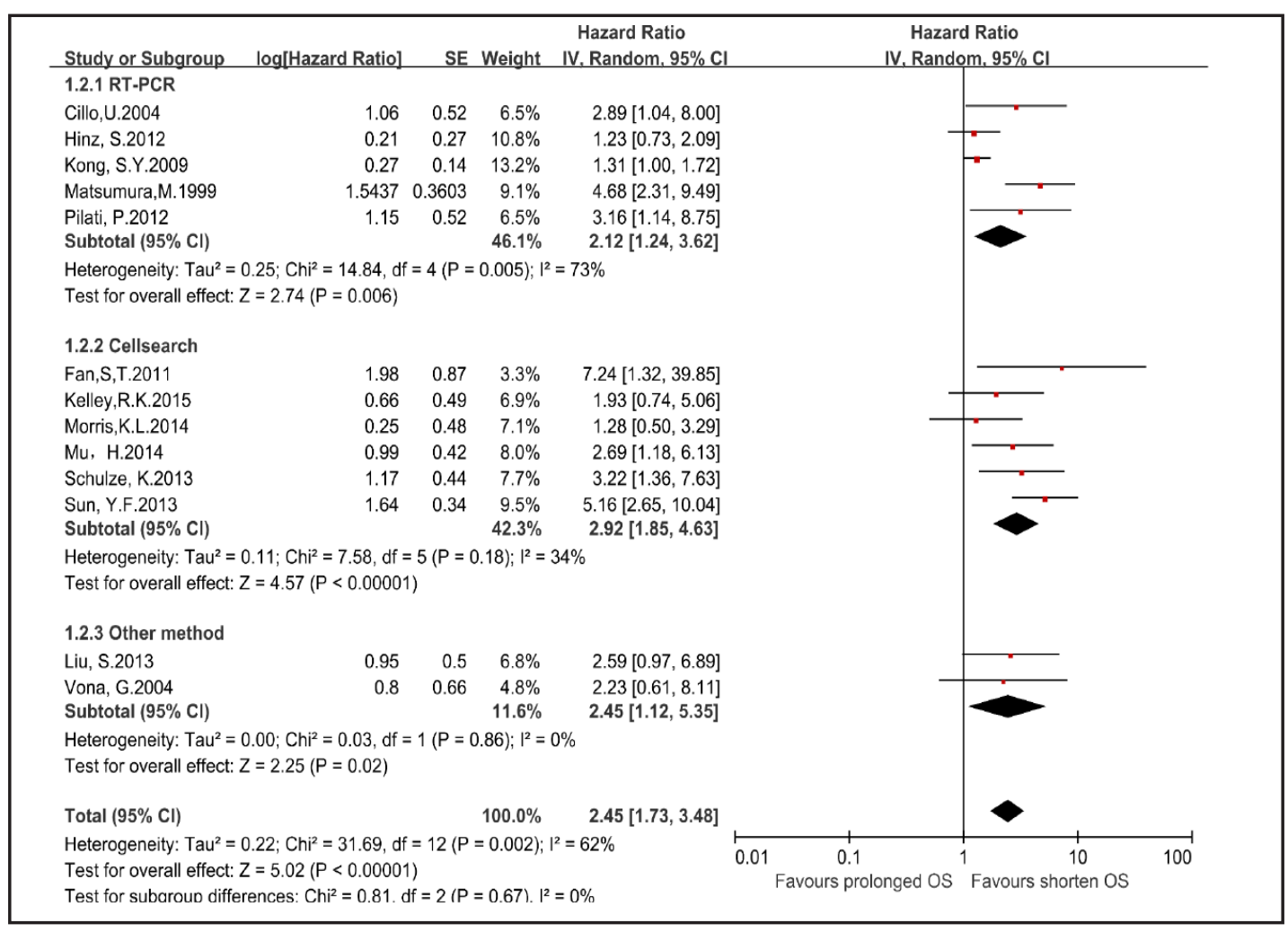

risk of death (HR 2.45, 95\% CI: [1.73-3.48]; $p<0.0001$ ) (Fig. 3), and the heterogeneity among studies was significant $\left(I^{2}=62 \%, p=0.002\right)$. We stratified studies of positive CTC detected by RT-PCR, Cell-search system and other ICC for subgroup, A similar trend was observed in the pooled analysis using the different methods (RT-PCR: HR 2.12, 95\% CI: [1.24-3.62, $p=0.006$; Cell-search system: HR 2.92, 95\% CI: [1.85-4.63], $p<0.00001$; other ICC: HR 2.45, 95\% CI: [1.12-5.35], $p=0.02)$.

\section{Correlation of Circulating Tumor Cells with Clinicopathologic Parameters}

When analyzed the association between CTC and other parameters, Relative Risk (RR) was calculated, RR $>1$ implied that CTC was associated with parameter. 9 studies $[22,28,31$, 38-43] reported the relationship between CTC positivity and TNM stage, the overall positive rate of CTC in stage I and II group was $43.71 \%$ compared with $56.28 \%$ of stage III and IV group. Pooled analysis showed that CTC positivity in stage III and IV is greater than that in stage I and II (RR=1.30, 95\% CI: [1.02-1.65]; $p=0.03$; random effects), with significant heterogeneity between studies $\left(\mathrm{I}^{2}=73 \%, p=0.0002\right)$ as shown in Fig. 4A. Tumor size [27, 28, 34-39, 41] (RR=1.36, 95\% CI: [1.09-1.69]; $p=0.006$; random effects) was associated with CTC positivity (Fig. 4B), the between-study heterogeneity was moderate $\left(I^{2}=33 \%, p=\right.$ $0.16)$. 8 studies $[22,27,30,33-35,38,39]$ analysis showed that positive CTC were associated with Vascular invasion (RR=1.99 95\% CI: [1.43-2.77]; $p<0.0001$; random effects) (Fig. 4C), the between-study heterogeneity was significant $\left(\mathrm{I}^{2}=49 \%, p=0.06\right) .8$ studies $[27,36-41]$ assessed the relationship between CTC positivity and portal vein tumor thrombus (RR 1.73, 95\% CI: [1.42-2.11]; $p<0.0001$; random effects) (Fig. 4D), the heterogeneity among studies was moderate $\left(\mathrm{I}^{2}=28 \%, p=0.20\right)$. The RRs for Tumor number were available in 6 studies $[22,27,34-36,40]$, the estimated pooled RR showed a trend towards greater numbers of CTC with more tumor number, but they did not achieve statistical significance $(p=0.07$. Fig. 4E). RRs for Serum AFP level were available in 8 studies [24, 27, 30, 31, 34, 37, 40, 42]. The estimated pooled RRs indicated that CTC was associated with AFP $\geq 400 \mathrm{ng} / \mathrm{mL}$ (RR 2.05, 
Fig. 4. Meta-analysis of the association between CTC and tumor-related parameters in HCC patients. (A), TNM stage; (B), Tumor size; (C), Vascular invasion; (D), Portal vein tumor thrombus; (E), Tumor number; (F), AFP level.

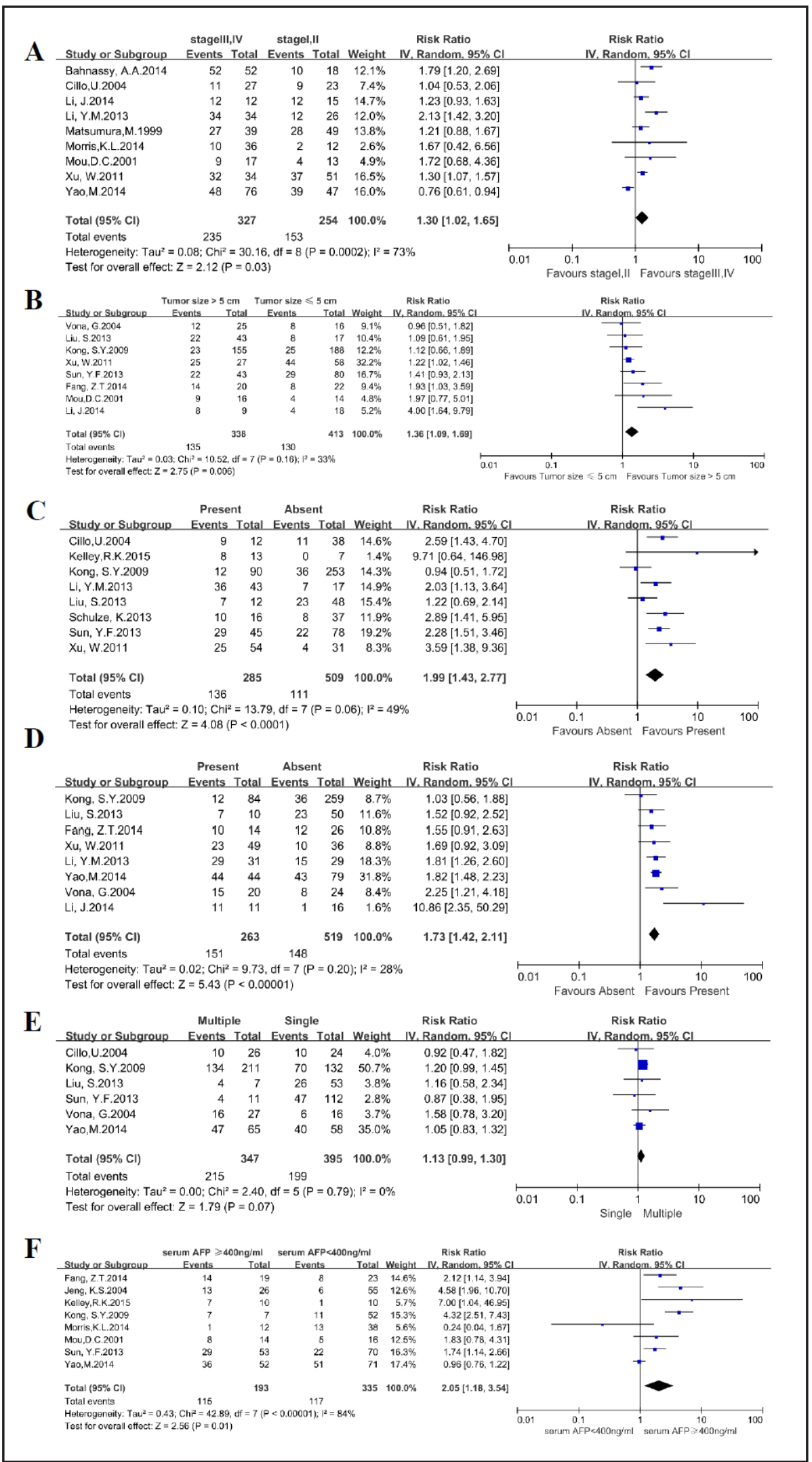

95\% CI: [1.18-3.54]; $p=0.01)$, the between-study heterogeneity was significant $\left(\mathrm{I}^{2}=84 \%\right.$, $p<0.000001$ ) (Fig. 4F). 
Fig. 5. Sensitivity analysis of the influence of each individual study on the pooled HRs by omitting individual studies.

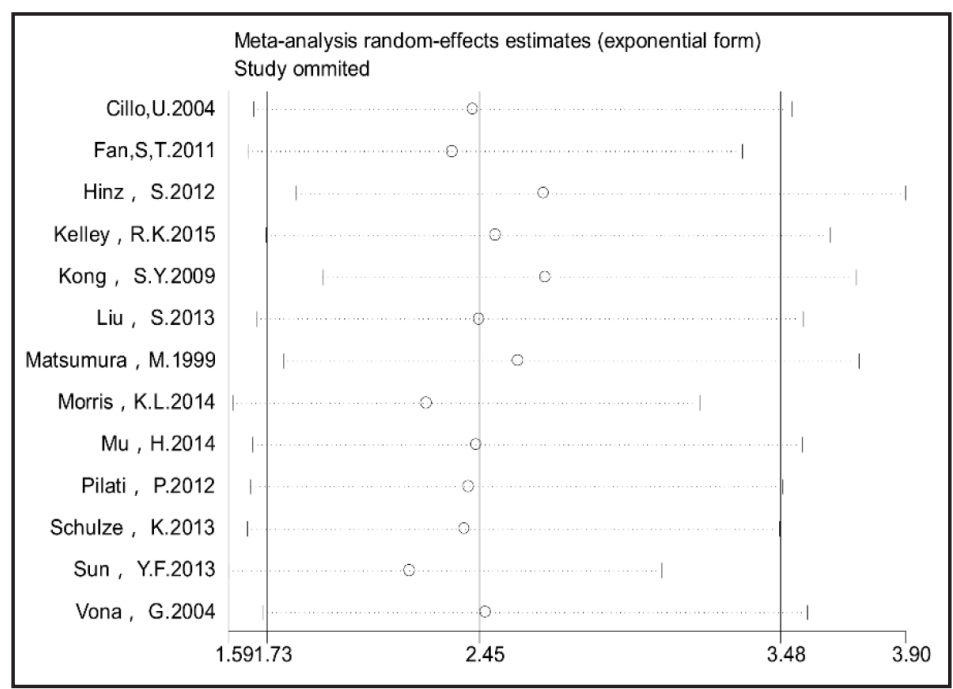

Fig. 6. The publication bias of this meta-analysis were assessed by Egger's linear regression test and Begg's funnel plots. Egger's linear regression test $(\mathrm{A})$ and Begg's funnel plots (B) of OS in patients with HCC. $\log [\mathrm{HR}]$ natural logarithm of HR; horizontal line mean magnitude of the effect. Each point represents a separate study for the indicated association. Note: A funnel plot with pseudo $95 \%$ confidence limits was used.

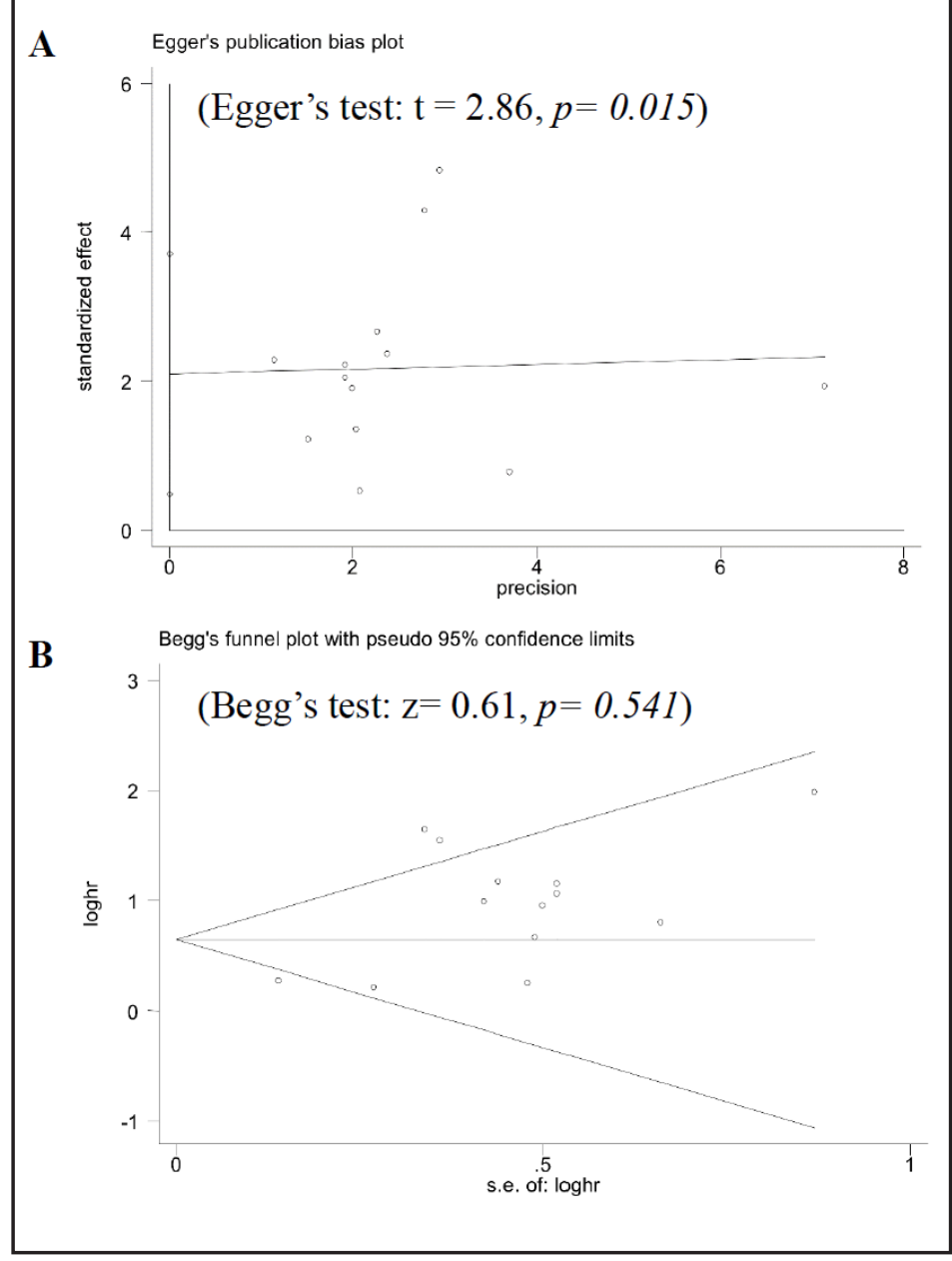

\section{Sensitivity analysis and publication bias}

Sensitivity analysis was conducted by deleting one single study from the overall pooled analysis each time, the result showed that neither the direction nor the magnitude of the estimated pooled results for OS was obviously affected, indicating that no single study dominated our results (Fig. 5). No significant publication bias was found in the pooled analysis of RFS tested by Begg's test ( $\mathrm{p}=0.541$, Fig. 6B). Furthermore, Egger's test (Fig. 6A) 
was performed to assess the publication bias of OS in this meta-analysis. The P value of the Egger's test was 0.015 , which was $>0.01$ but $<0.05$, it indicates that there is publication bias existed in this meta-analysis.

\section{Discussion}

Numerous studies have showed that the presence of CTC was significantly associated with prognosis or other clinicopathologic parameters in hepatocellular carcinoma. While, the lack of statistical power together with their different studies design and results limited the individual clinical value with the prognostic effect of CTC positivity, the clinical significance of CTC in HCC patients has not yet been confirmed, and whether CTC can be used as a predictive marker for prognosis is controversial.

The results of our meta-analysis show that CTC positivity was associated with poor RFS and OS, significantly increased risk of disease recurrence and death. Moreover, we evaluated the correlation of CTC with the main HCC clinical pathological parameters. Significant correlations were observed between CTC detected in the blood and TNM stage, tumor size, vascular invasion, Portal vein tumor thrombus, tumor number or serum AFP level, but not with tumor number. Thus, CTC positivity in peripheral blood of HCC patients should indeed be considered as a prognostic marker. A sensitivity analysis, performed by removing each study individually, confirmed the stability of our results.

However, during the process of our meta-analysis, several limitations must be noted. We noticed a certain degree of heterogeneity, and potential sources of heterogeneity may derive from the follows: Firstly, different in demographic, clinicopathologic data or characteristics (i.e. age, sex and race) of included patients, particularly, the etiological factors of HCC. The different etiologies include hepatitis B virus (HBV) and hepatitis C virus (HCV) infection, chronic alcohol abuse, non-alcoholic steatohepatitis (NASH), autoimmune hepatitis, liver metastases from other types of cancer and so on. Hepatitis is the leading cause of HCC in Asia, while in Europe, the majority of cases was based on heavy chronic alcohol abuse. Therefore, the integration of CTC detection in homogeneous patients may more accurately predict the tumor response. Secondly, types of target tumor markers, standard of CTC positivity and detection method. The hepatocellular carcinomas can synthesize various tumor-related proteins, polypeptides, and isoenzymes more or less specific of the hepatoma tissues as well as the corresponding mRNA $[50,51]$. We observed that many specific HCC markers are available and useful for the detection of the CTC, duo to the heterogeneity of the hepatocellular carcinoma, at least partly. About the standard of CTC positivity, the cutoff value and blood collection were different among studies. Different methods have different definitions, Furthermore, the definitions of CTC positivity and blood collection in the studies that using the same method such as ICC were also different. Various methods have been developed and optimized for CTC detection. Immunocytochemistry (ICC) and reverse transcriptase polymerase chain reaction (RT-PCR) are the two main approaches currently. Real-time polymerase chain reaction is a method that in addition to be specific by the nature of the primers used which can specifically amplify the number of copies of mRNA originally presents in the sample, such as AFP mRNA. Among various ICC methods, the Cell-search system is the only assay authorized by the U.S. Food and Drug Administration (FDA) for clinical use. This system is mainly based on semiautomatic isolation of epithelial tumor cells using immunomagnetic separation technology, and has been widely used in a number of malignancies, mainly is breast cancer [52-54]. In our analysis, the number of studies using RT-PCR to detect CTC is nearly equal to the number of studies using ICC. Subgroup analyses for OS stratified by detection method were performed. Subgroup analysis pooled HRs for OS are stably statistically significant in RT-PCR, Cell-search and other ICC subgroups with no heterogeneity. The pooled results are fairly stable and not influenced by the CTC detection method firmly provides evidence that the presence of CTC in peripheral blood indicates poor prognosis in patients with HCC. In addition, sampling time, also an important factor that

\section{KARGER}


leads to heterogeneity and interferes the prognostic value of CTC positivity. Huang, et al [55] found that the prognostic and predictive significance of CTC was relevant to CTC sampling time through analyzed the effect of CTC as a predictive biomarker according to different sampling times.

We addressed the issue of heterogeneity by a rigorous methodological approach that used the random-effects model for more conservative estimates. However, heterogeneity could be decreased but not eliminated. Something else was also responsible for the limitations. Firstly, it is the inability to access primary data of the included studies. Prognostic factors of hepatocellular carcinoma are complicated, while there is very limited data on the clinical relevance of CTC positivity in HCC patients. Our data for meta-analysis was from the included studies and primary data was inaccessible, thus, we were unable to exclude every possible confounding factor. Moreover, several studies did not provide HRs directly and we must estimate them from the available data according to the method reported by Tierney J.F. [48]. Furthermore, studies introduced to pooled analysis have relatively small sample size and language restriction of our analysis to published studies written in English, may also result in publication bias. Our meta-analysis also indicates that CTC were associated with the RFS and OS and clinical pathological parameters (TNM stage, tumor size, vascular invasion, portal vein tumor thrombus, AFP level) of HCC patients, although we were unable to conduct analyses considering certain potentially relevant factors.

In conclusion, the present results support the notion of a strong prognostic value of CTC in HCC. CTC could be useful as an effective indicator to evaluate the poor clinicopathological prognostic factors in the progression of HCC. In future, well-designed, large-scale, detailed and accurate studies are required to explore CTC predictive value for the prognosis of patients with HCC.

\section{Acknowledgments}

This work was supported by National Natural Science Foundation of China (No. 81371897), and Natural Science Foundation of Hubei Province (No. 2013CFA027), and research grants from Funded by Independent Research Fund Program of Wuhan University ( No.2042014kf0241),and Hubei Province health and family planning scientific research project(WJ2015MB032). This work was also funded by "351 talent project (Luojia Young Scholars)" of Wuhan University.

\section{Disclosure Statement}

No potential conflicts of interest were disclosed.

\section{References}

1 Hussain K, El-Serag HB: Epidemiology, screening, diagnosis and treatment of hepatocellular carcinoma. Minerva Gastroenterol Dietol 2009;55:123-138.

2 Caldwell S, Park S H: The epidemiology of hepatocellular cancer: from the perspectives of public health problem to tumor biology. J Gastroenterol 2009;44:96-101.

3 Forner A, Llovet J M, Bruix J: Hepatocellular carcinoma. Lancet 2012;379:1245-1255.

4 Britto M R, Thomas L A, Balaratnam N, Griffiths A P, Duane P D: Hepatocellular carcinoma arising in noncirrhotic liver in genetic haemochromatosis. Scand J Gastroenterol 2000;35:889-893.

5 Sanchez Antolin G, Garcia Pajares F, Perez E, Villacastin E, Ruiz Rebollo L, Sanchez D P, Citores M A, Velicia Llames R: Milan criteria versus San Francisco criteria in hepatocellular carcinoma: our center's experience. Transplant Proc 2009;41:1012-1013. 
6 Schuler F, Dolken G: Detection and monitoring of minimal residual disease by quantitative real-time PCR. Clin Chim Acta 2006;363:147-156.

7 Dardaei L, Shahsavani R, Ghavamzadeh A, Behmanesh M, Aslankoohi E, Alimoghaddam K, Ghaffari S H: The detection of disseminated tumor cells in bone marrow and peripheral blood of gastric cancer patients by multimarker (CEA, CK20, TFF1 and MUC2) quantitative real-time PCR. Clin Biochem 2011;44:325-330.

8 Chaffer C L, Weinberg R A: A perspective on cancer cell metastasis. Science 2011;331:1559-1564.

9 Bidard F C, Mathiot C, Delaloge S, Brain E, Giachetti S, de Cremoux P, Marty M, Pierga J Y: Single circulating tumor cell detection and overall survival in nonmetastatic breast cancer. Ann Oncol 2010;21:729-733.

10 Koga T, Tokunaga E, Sumiyoshi Y, Oki E, Oda S, Takahashi I, Kakeji Y, Baba H, Maehara Y: Detection of circulating gastric cancer cells in peripheral blood using real time quantitative RT-PCR. Hepatogastroenterology 2008;55:1131-1135.

11 Arigami T, Uenosono Y, Hirata M, Yanagita S, Ishigami S, Natsugoe S: B7-H3 expression in gastric cancer: a novel molecular blood marker for detecting circulating tumor cells. Cancer Sci 2011;102:1019-1024.

12 Qiu M Z, Li Z H, Zhou Z W, Li Y H, Wang Z Q, Wang F H, Huang P, Aziz F, Wang D Y, Xu R H: Detection of carcinoembryonic antigen messenger RNA in blood using quantitative real-time reverse transcriptasepolymerase chain reaction to predict recurrence of gastric adenocarcinoma. J Transl Med 2010;8:107.

13 Reeh M, Effenberger K E, Koenig A M, Riethdorf S, Eichstadt D, Vettorazzi E, Uzunoglu F G, Vashist Y K, Izbicki J R, Pantel K, Bockhorn M: Circulating Tumor Cells as a Biomarker for Preoperative Prognostic Staging in Patients With Esophageal Cancer. Ann Surg DOI: 10.1097/SLA.0000000000001130.

14 Winters B, James A, Lee J, Kho J, Morrissey C, Wright J: Chemotherapeutic effects on circulating tumor cells in bladder cancer. Int J Urol 2015;22:612-613.

15 Breitenbuecher F, Hoffarth S, Worm K, Cortes-Incio D, Gauler T C, Kohler J, Herold T, Schmid K W, Freitag L, Kasper S, Schuler M: Development of a highly sensitive and specific method for detection of circulating tumor cells harboring somatic mutations in non-small-cell lung cancer patients. PLoS One 2014;9:e85350.

16 Skondra M, Gkioka E, Kostakis I D, Pissimissis N, Lembessis P, Pectasides D, Koutsilieris M: Detection of circulating tumor cells in breast cancer patients using multiplex reverse transcription-polymerase chain reaction and specific primers for MGB, PTHRP and KRT19 correlation with clinicopathological features. Anticancer Res 2014;34:6691-6699.

17 Gu Y, Ju C, Li Y, Shang Z, Wu Y, Jia Y, Niu Y: Detection of circulating tumor cells in prostate cancer based on carboxylated graphene oxide modified light addressable potentiometric sensor. Biosens Bioelectron 2015;66:24-31.

18 Katoh S, Goi T, Naruse T, Ueda Y, Kurebayashi H, Nakazawa T, Kimura Y, Hirono Y, Yamaguchi A: Cancer stem cell marker in circulating tumor cells: expression of CD44 variant exon 9 is strongly correlated to treatment refractoriness, recurrence and prognosis of human colorectal cancer. Anticancer Res 2015;35:239-244.

19 Cohen S J, Punt C J, Iannotti N, Saidman B H, Sabbath K D, Gabrail N Y, Picus J, Morse M, Mitchell E, Miller M C, Doyle G V, Tissing H, Terstappen L W, Meropol N J: Relationship of circulating tumor cells to tumor response, progression-free survival, and overall survival in patients with metastatic colorectal cancer. J Clin Oncol 2008;26:3213-3221.

20 Wang H Y, Ahn S, Kim S, Park S, Jung D, Han H, Sohn J, Lee H: Detection of circulating tumor cell-specific markers in breast cancer patients using the quantitative RT-PCR assay. Int J Clin Oncol DOI:10.1007/ s10147-015-0798-3.

21 Choi G H, Kim G I, Yoo J E, Na D C, Han D H, Roh Y H, Park Y N, Choi J S: Increased Expression of Circulating Cancer Stem Cell Markers During the Perioperative Period Predicts Early Recurrence After Curative Resection of Hepatocellular Carcinoma. Ann Surg Oncol DOI:10.1245/s10434-015-4480-9.

22 Cillo U, Navaglia F, Vitale A, Molari A, Basso D, Bassanello M, Brolese A, Zanus G, Montin U, D'Amico F, Ciarleglio F A, Carraro A, Bridda A, Burra P, Carraro P, Plebani M, D'Amico D F: Clinical significance of alphafetoprotein mRNA in blood of patients with hepatocellular carcinoma. Clin Chim Acta 2004;347:129-138.

23 Fan S T, Yang Z F, Ho D W, Ng M N, Yu W C, Wong J: Prediction of posthepatectomy recurrence of hepatocellular carcinoma by circulating cancer stem cells: a prospective study. Ann Surg 2011;254:569576.

24 Jeng K S, Sheen I S, Tsai Y C: Does the presence of circulating hepatocellular carcinoma cells indicate a risk of recurrence after resection? Am J Gastroenterol 2004;99:1503-1509. 
25 Rahbari N N, Reissfelder C, Muhlbayer M, Weidmann K, Kahlert C, Buchler M W, Weitz J, Koch M: Correlation of circulating angiogenic factors with circulating tumor cells and disease recurrence in patients undergoing curative resection for colorectal liver metastases. Ann Surg Oncol 2011;18:2182-2191.

26 Hinz S, Bockhorst J, Roder C, Egberts J H, Schafmayer C, Kuchler T, Becker T, Kalthoff H: Disseminated tumor cells in the bone marrow negatively influence survival after resection of colorectal liver metastases. Ann Surg Oncol 2012;19:2539-2546.

27 Kong S Y, Park J W, Kim J O, Lee N O, Lee J A, Park K W, Hong E K, Kim C M: Alpha-fetoprotein and human telomerase reverse transcriptase mRNA levels in peripheral blood of patients with hepatocellular carcinoma. J Cancer Res Clin Oncol 2009;135:1091-1098.

28 Matsumura M, Shiratori Y, Niwa Y, Tanaka T, Ogura K, Okudaira T, Imamura M, Okano K, Shiina S, Omata M: Presence of alpha-fetoprotein mRNA in blood correlates with outcome in patients with hepatocellular carcinoma. J Hepatol 1999;31:332-339.

29 Pilati P, Mocellin S, Bertazza L, Galdi F, Briarava M, Mammano E, Tessari E, Zavagno G, Nitti D: Prognostic value of putative circulating cancer stem cells in patients undergoing hepatic resection for colorectal liver metastasis. Ann Surg Oncol 2012;19:402-408.

30 Kelley R K, Magbanua M J, Butler T M, Collisson E A, Hwang J, Sidiropoulos N, Evason K, McWhirter R M, Hameed B, Wayne E M, Yao F Y, Venook A P, Park J W: Circulating tumor cells in hepatocellular carcinoma: a pilot study of detection, enumeration, and next-generation sequencing in cases and controls. BMC Cancer 2015;15:206.

31 Morris K L, Tugwood J D, Khoja L, Lancashire M, Sloane R, Burt D, Shenjere P, Zhou C, Hodgson C, Ohtomo T, Katoh A, Ishiguro T, Valle J W, Dive C: Circulating biomarkers in hepatocellular carcinoma. Cancer Chemother Pharmacol 2014;74:323-332.

32 Mu H, Lin K X, Zhao H, Xing S, Li C, Liu F, Lu H Z, Zhang Z, Sun Y L, Yan X Y, Cai J Q Zhao X H: Identification of biomarkers for hepatocellular carcinoma by semiquantitative immunocytochemistry. World J Gastroenterol 2014;20:5826-5838.

33 Schulze K, Gasch C, Staufer K, Nashan B, Lohse A W, Pantel K, Riethdorf S, Wege H: Presence of EpCAMpositive circulating tumor cells as biomarker for systemic disease strongly correlates to survival in patients with hepatocellular carcinoma. Int J Cancer 2013;133:2165-2171.

34 Sun Y F, Xu Y, Yang X R, Guo W, Zhang X, Qiu S J, Shi R Y, Hu B, Zhou J, Fan J: Circulating stem cell-like epithelial cell adhesion molecule-positive tumor cells indicate poor prognosis of hepatocellular carcinoma after curative resection. Hepatology 2013;57:1458-1468.

35 Liu S, Li N, Yu X, Xiao X, Cheng K, Hu J, Wang J, Zhang D, Cheng S: Expression of intercellular adhesion molecule 1 by hepatocellular carcinoma stem cells and circulating tumor cells. Gastroenterology 2013;144:1031-1041.

36 Vona G, Estepa L, Beroud C, Damotte D, Capron F, Nalpas B, Mineur A, Franco D, Lacour B, Pol S, Brechot C, Paterlini-Brechot $\mathrm{P}$ : Impact of cytomorphological detection of circulating tumor cells in patients with liver cancer. Hepatology 2004;39:792-797.

37 Fang Z T, Zhang W, Wang G Z, Zhou B, Yang G W, Qu X D, Liu R, Qian S, Zhu L, Liu L X, Wang J H: Circulating tumor cells in the central and peripheral venous compartment - assessing hematogenous dissemination after transarterial chemoembolization of hepatocellular carcinoma. Onco Targets Ther 2014;7:1311-1318.

38 Xu W, Cao L, Chen L, Li J, Zhang X F, Qian H H, Kang X Y, Zhang Y, Liao J, Shi L H, Yang Y F, Wu M C, Yin Z F: Isolation of circulating tumor cells in patients with hepatocellular carcinoma using a novel cell separation strategy. Clin Cancer Res 2011;17:3783-3793.

39 Li Y M, Xu S C, Li J, Han K Q Pi H F, Zheng L, Zuo G H, Huang X B, Li H Y, Zhao H Z, Yu Z P, Zhou Z, Liang $P$ : Epithelial-mesenchymal transition markers expressed in circulating tumor cells in hepatocellular carcinoma patients with different stages of disease. Cell Death Dis 2013;4:e831.

40 Yao M, Yao D F, Bian Y Z, Wu W, Yan X D, Yu D D, Qiu L W, Yang J L, Zhang H J, Sai W L, Chen J: Values of circulating GPC-3 mRNA and alpha-fetoprotein in detecting patients with hepatocellular carcinoma. Hepatobiliary Pancreat Dis Int 2013;12:171-179.

41 Li J, Chen L, Zhang X, Zhang Y, Liu H, Sun B, Zhao L, Ge N, Qian H, Yang Y, Wu M, Yin Z: Detection of circulating tumor cells in hepatocellular carcinoma using antibodies against asialoglycoprotein receptor, carbamoyl phosphate synthetase 1 and pan-cytokeratin. PLoS One 2014;9:e96185. 
42 Mou D C, Cai S L, Peng J R, Wang Y, Chen H S, Pang X W, Leng X S, Chen W F: Evaluation of MAGE-1 and MAGE-3 as tumour-specific markers to detect blood dissemination of hepatocellular carcinoma cells. $\mathrm{Br} \mathrm{J}$ Cancer 2002;86:110-116.

43 Bahnassy A A, Zekri A R, El-Bastawisy A, Fawzy A, Shetta M, Hussein N, Omran D, Ahmed A A, El-Labbody S S: Circulating tumor and cancer stem cells in hepatitis $C$ virus-associated liver disease. World J Gastroenterol 2014;20:18240-18248.

44 Stang A: Critical evaluation of the Newcastle-Ottawa scale for the assessment of the quality of nonrandomized studies in meta-analyses. Eur J Epidemiol 2010; 25: 603-605.

45 Zhang D, Chen L, Peng K, Xing F, Wang H, Xiang Z: Effectiveness and safety of the posterior approach with soft tissue repair for primary total hip arthroplasty: a meta-analysis. Orthop Traumatol Surg Res 2015;101:39-44.

46 Deshpande A, Pasupuleti V, Thota P, Pant C, Rolston D D, Sferra T J, Hernandez A V, Donskey C J: Community-associated Clostridium difficile infection and antibiotics: a meta-analysis. J Antimicrob Chemother 2013;68:1951-1961.

47 Ding M, Bhupathiraju S N, Chen M, van Dam R M, Hu F B: Caffeinated and decaffeinated coffee consumption and risk of type 2 diabetes: a systematic review and a dose-response meta-analysis. Diabetes Care 2014;37:569-586.

48 Tierney J F, Stewart L A, Ghersi D, Burdett S, Sydes M R: Practical methods for incorporating summary timeto-event data into meta-analysis. Trials 2007;8:16.

49 Egger M, Davey Smith G, Schneider M, Minder C: Bias in meta-analysis detected by a simple, graphical test. BMJ 1997;315:629-634.

50 Zhou J, Lu S, Yang S, Chen H, Shi H, Miao M, Jiao B: MicroRNA-127 post-transcriptionally downregulates Sept7 and suppresses cell growth in hepatocellular carcinoma cells. Cell Physiol Biochem 2014;33:15371546.

51 Jiang H L, Xu D, Yu H, Ma X, Lin G F, Ma D Y, Jin J Z: DAX-1 inhibits hepatocellular carcinoma proliferation by inhibiting beta-catenin transcriptional activity. Cell Physiol Biochem 2014;34:734-742.

52 Riethdorf S, Fritsche H, Muller V, Rau T, Schindlbeck C, Rack B, Janni W, Coith C, Beck K, Janicke F, Jackson S, Gornet T, Cristofanilli M, Pantel K: Detection of circulating tumor cells in peripheral blood of patients with metastatic breast cancer: a validation study of the CellSearch system. Clin Cancer Res 2007;13:920-928.

53 Muller V, Riethdorf S, Rack B, Janni W, Fasching P A, Solomayer E, Aktas B, Kasimir-Bauer S, Pantel K, Fehm T: Prognostic impact of circulating tumor cells assessed with the CellSearch System and AdnaTest Breast in metastatic breast cancer patients: the DETECT study. Breast Cancer Res 2012;14:R118.

54 Miller M C, Doyle G V, Terstappen L W: Significance of Circulating Tumor Cells Detected by the CellSearch System in Patients with Metastatic Breast Colorectal and Prostate Cancer. J Oncol 2010;2010:617421.

55 Huang X, Gao P, Song Y, Sun J, Chen X, Zhao J, Liu J, Xu H, Wang Z: Relationship between circulating tumor cells and tumor response in colorectal cancer patients treated with chemotherapy: a meta-analysis. BMC Cancer 2014;14:976. 